\title{
Review
}

\section{Global Perspective on Telemedicine for Parkinson's Disease}

\author{
Ali Shalash ${ }^{\mathrm{a}}$, Meredith Spindler ${ }^{\mathrm{b}}$ and Esther $\mathrm{Cubo}^{\mathrm{c}, *}$ \\ ${ }^{a}$ Department of Neurology, Faculty of Medicine, Ain Shams University, Cairo, Egypt \\ ${ }^{\mathrm{b}}$ Department of Neurology, University of Pennsylvania, Philadelphia, PA, USA \\ ${ }^{\mathrm{c}}$ Neurology Department, Hospital University of Burgos, Burgos, Spain
}

Accepted 18 January 2021

Pre-press 8 February 2021

\begin{abstract}
Telemedicine programs are particularly suited to evaluating patients with Parkinson's disease (PD) and other movement disorders, primarily because much of the physical exam findings are visual. Telemedicine uses information and communication technologies to overcome geographical barriers and increase access to healthcare service. It is particularly beneficial for rural and underserved communities, groups that traditionally suffer from lack of access to healthcare. There is a growing evidence of the feasibility of telemedicine, cost and time savings, patients' and physicians' satisfaction, and its outcome and impact on patients' morbidity and quality of life. In addition, given the unusual current situation with the COVID-19 pandemic, telemedicine has offered the opportunity to address the ongoing healthcare needs of patients with $\mathrm{PD}$, to reduce in-person clinic visits, and human exposures (among healthcare workers and patients) to a range of infectious diseases including COVID-19. However, there are still several challenges to widespread implementation of telemedicine including the limited performance of parts of the neurological exam, limited technological savvy, fear of loss of a personal connection, or uneasiness about communicating sensitive information. On the other hand, while we are facing the new wave of COVID-19 pandemic, patients and clinicians are gaining increasing experience with telemedicine, facilitating equity of access to specialized multidisciplinary care for PD. This article summarizes and reviews the current state and future directions of telemedicine from a global perspective.
\end{abstract}

Keywords: Telemedicine, telehealth, movement disorders, Parkinson's disease

\section{INTRODUCTION}

Traditional medical practice is not always the most efficient or convenient way to provide care to patients with movement disorders. The prevalence of neurodegenerative disorders is increasing globally as the population ages. The scarcity of established modifiable risks for most of the neurological disease burden and the shortage of neurological services necessitates both the development of effective prevention and treatment strategies and ways to ensure

\footnotetext{
${ }^{*}$ Correspondence to: Esther Cubo MD, PhD, Neurology Department, University Hospital, Burgos, Spain. E-mail: mcubo@ saludcastillayleon.es.
}

equitable access [1, 2]. Information and communication technologies (ICTs) have great potential to address some of the challenges both developed, and developing countries face in providing accessible, cost-effective, and high-quality health care services. Telemedicine uses ICTs to overcome geographical barriers and increase access to healthcare services, and it is particularly beneficial for rural and underserved communities, groups that traditionally suffer from lack of access to healthcare [3].

Telemedicine programs are particularly suited to evaluating patients with Parkinson's disease (PD) and other movement disorders, primarily because many of the physical exam findings are visual. Telemedicine offers the opportunity for enhanced access 
to specialty care, thus potentially reducing delayed diagnosis, delay in treatments and subsequent morbidity and mortality, and improving quality of life (QoL) for patients with PD and other movement disorders [4]. The inherent attraction of telemedicine is its ability to bridge the major barriers that limit such access, including distance, disability, and distribution of qualified health providers [5]. Furthermore, the typical outpatient visit to the clinic offers face to face contact, but is, at best, a very crude and often inaccurate perspective of the patient's real functioning at home, whereas telemedicine allows providers to judge patients in their own natural environment. This article aimed to provide a global perspective on the current and future aspects of telemedicine in PD, describing feasibility, outcomes, users perceptions, current barriers and challenges, and use during unusual situations such as the coronavirus 2019 (COVID-19) pandemic.

\section{CURRENT PERSPECTIVES OF PD TELEMEDICINE}

Several determinants of telemedicine for PD have been described including feasibility, cost and time savings, patients' and physicians' satisfaction, and its outcome and impact on patients' QoL). The high feasibility of virtual visits for PD has been demonstrated by several randomized and non-randomized studies [6-9]. Feasibility was measured as the percentage of completed virtual visits as scheduled and ranged from 81-100\% [6, 10]. Furthermore, longitudinal studies showed sustained high feasibility for up to 3 years [11]. The outcome of virtual visits includes valid assessment, management of symptoms, and patients' functioning and QoL $[5,12]$. Randomized controlled studies showed comparable QoL outcomes of virtual sessions to in-person usual visits $[6,7,13]$. Furthermore, cost, travel and time saving is one of the advantages of telemedicine for patients with PD that increases patients' access to healthcare. Telemedicine studies showed saved costs (up to \$370), travel time (up to 3 hours), travel kilometers per patient (up to $160 \mathrm{~km}$ ), and time spent without physicians for patients $[6,7,11,13]$. From the perspective of patients with $\mathrm{PD}$, access to specialists (62\%), virtual visits convenience (60\%), and time savings (59\%) were the top advantages of telemedicine [14].

Additionally, patients' and physicians' satisfaction is essential for the adoption of telemedicine. Several studies reported high patients' satisfaction of virtual visits (up to $97 \%$ ), with $74-85 \%$ willing to continue using telemedicine $[6,9,11]$. Patients' satisfaction emanated from substantial personal benefit, high quality of care, and good interpersonal engagement; however, technical problems with the software had a negative impact $[8,15]$. Similarly, physicians showed high satisfaction with virtual visits [9]. Most of these studies were conducted in developed countries; however, a recent study from a developing country during COVID-19 similarly showed high feasibility, satisfaction, and service quality of virtual visits [16]. Therefore, telemedicine is considered a feasible, costeffective approach of healthcare of patients with PD, with a satisfactory outcome and high patient and physician satisfaction. However, to understand the global advantages of telemedicine around the world, further studies are warranted from different countries and health care settings.

\section{CURRENT APPLICATIONS OF TELEMEDICINE FOR PD}

Currently, several applications of telemedicine for PD have been adopted. Many studies applied the use of synchronous and remote follow-up visits to enable face-to-face virtual interaction and increase patients' access to specialized health care [6, 17, 18]. Moreover, synchronous virtual visits allow remote motor assessment including the use of a modified version of MDS-UPDRS, remote assessment for cognition, genetic testing, and clinical studies [17, 1922]. On the other hand, asynchronous assessments were reported using remotely recorded and uploaded videos and remote telemetry monitoring [23]. Remote telemetry monitoring includes the use of specialized devices, wearable sensors, and mobile applications for motor evaluation such as tremor, bradykinesia, gait, falls, and speech [24]. Remote delivery of various rehabilitation services, especially speech therapy and physiotherapy, has been employed. Different virtual programs that promote and coach patients' exercise, in addition to physiotherapy training, have been developed [25-27]. Many physical therapists have begun using telemedicine during the pandemic, though balance evaluations are challenging via video. Previous studies demonstrated the feasibility and effectiveness of synchronous vocal telerehabilitation, using the Lee Silverman Voice Treatment (LSVT) [28, 29]. Meanwhile, few reports have investigated the validity and reliability of telerehabilitation for dysphagia that included PD patients [30, 


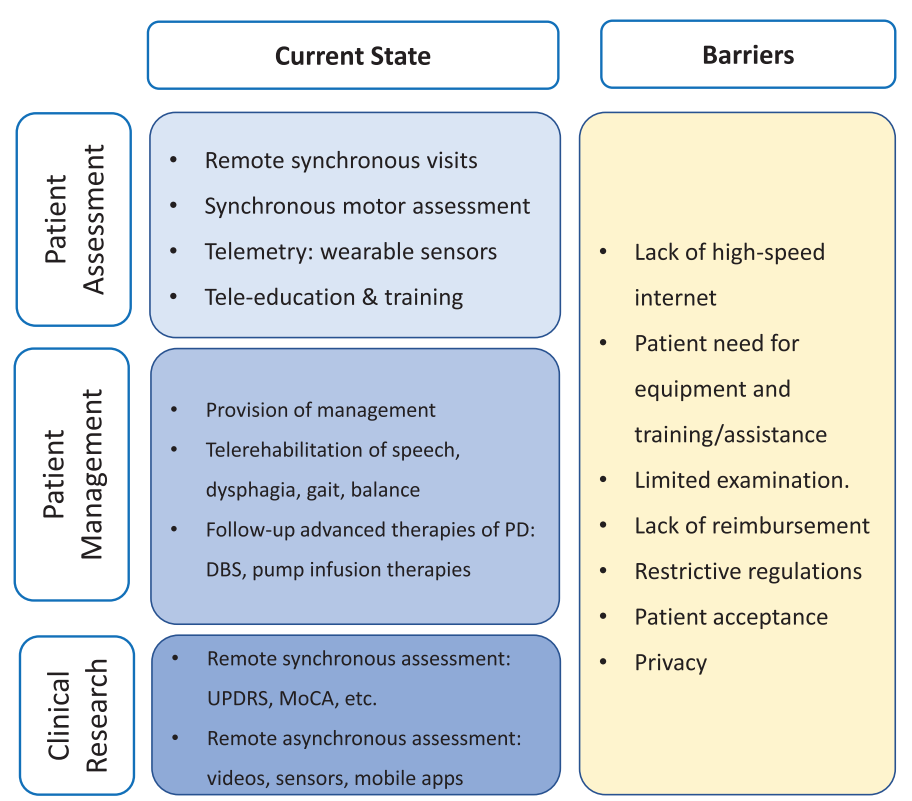

Access to health care

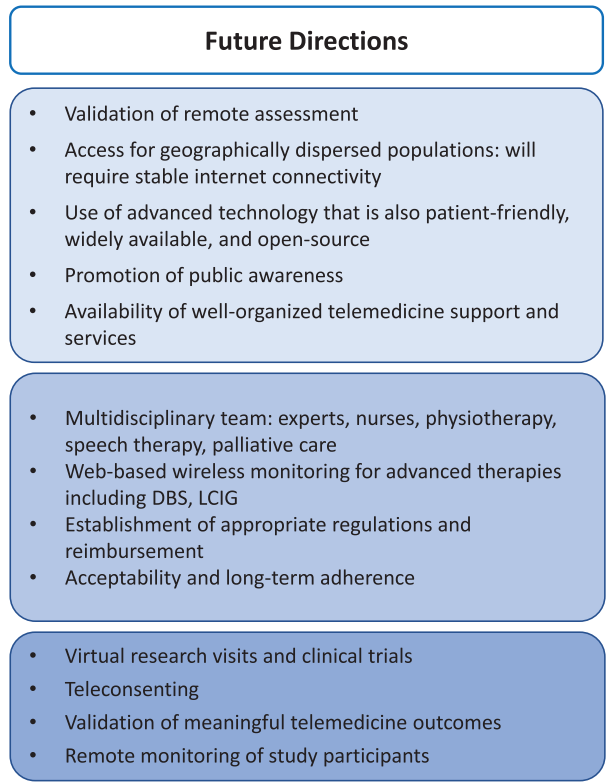

Well organized patient-centered interdisciplinary care

Fig. 1. Telemedicine interdisciplinary approach.

31]. Additionally, psychotherapy via telemedicine have been shown to be feasible in small studies [32].

Virtual monitoring of advanced PD therapies has recently been applied. For example, the Ontario group reported their experience in the evaluation and follow-up of patients with DBS [33]. Additionally, web-based wireless DBS programming systems are currently provided by two DBS manufacturers in China (PINS and SceneRay) and applied to adjust DBS settings remotely [34]. Meanwhile, Willows et al. reported that telemedicine-assisted levodopacarbidopa intestinal gel (LCIG) titration at home was resource-efficient, technically feasible, well-accepted, and satisfactory by patients, neurologists, and nurses [35].

Moreover, telemedicine could provide access to Interdisciplinary healthcare systems, including movement disorders experts, specialized speech therapists and physiotherapists, specialized nurses, and support groups (Fig. 1). Exemplars of well-established multidisciplinary networks include the Department of Veterans Affairs (USA), Ontario Telemedicine Network (Canada), and ParkinsonNet (Netherlands) [5]. In addition to the clinical applications, telemedicine could provide education and training for physicians and other health professionals in developing countries, which lack experts, and overcome barriers of travel restrictions and costs [36]. For example, Cubo et al. reported successful training and education programs that targeted health professionals in Cameroon [37]. Additionally, the international Parkinson and Movement Disorder Society (MDS) supports several online educational activities through the "virtual professor program" and asynchronous video consultations for African physicians via the "Asynchronous Consultation for Movement Disorders" program.

\section{GLOBAL TELEMEDICINE USE FOR PD}

Existing data on global telemedicine use for movement disorders was first collected in 2015 via a survey of members of the MDS [38]. Of over 500 survey respondents from 83 countries, approximately half were engaged in telemedicine for movement disorders. Sixty-three percent of respondents reported using email communication, and despite barriers such as lack of reimbursement and technological difficulties, $40 \%$ reported use of video visits for return visits at their institution, and a slightly lower percentage (35\%) reported use of video visits for new patients. Thirty-five percent used videoconferencing for education at their institution. Half of respondents planned to use telemedicine in the future, and threequarters desired telemedicine education. However, the barriers to telemedicine identified in 2015 such as privacy issues and technical limitations mostly remain unchanged [39]. 
In 2020, the MDS Telemedicine Study Group surveyed members from 40 countries regarding telemedicine use for movement disorders both before and during the pandemic. Four domains of telemedicine such as legal regulations, reimbursement, clinical usage, barriers were compared prior to and just after the COVID-19 Pandemic. Countries represented included 4 from Europe, 5 from North America, 3 from Central America, 6 from South America, 6 from East Asia, 10 countries in Africa, Australia, New Zealand, Pakistan, Israel, and Saudi Arabia. Twentyseven countries $(67.5 \%)$ specifically reported using video visits prior to the pandemic, while the remainder reported using phone calls, emails, or texts, or did not specify. Though specific software was not always mentioned, the most commonly cited platform was WhatsApp, reported by 14 countries; Zoom and Skype were also frequently mentioned. Prior to COVID-19, half of the countries had legal regulations regarding the use of telemedicine, and these were distributed over all continents represented. Telemedicine was illegal in only one country, South Korea. Similarly, reimbursement varied widely, with approximately two thirds of countries having reimbursement options for at least some cases, while third of countries reported no reimbursement option. It should be noted that data regarding the prevalence of use was not collected, and these were the perspectives of individual movement disorders practitioners in each country [39].

\section{TELEMEDICINE DURING UNUSUAL SITUATIONS: COVID-19 PANDEMIC}

On March 11, 2020, the WHO declared the CO VID-19 outbreak as a pandemic. Consequently, many countries have taken drastic measures to slow down infection rates, including physical and social distancing, and in some countries, a lock-down of nonessential business. The first healthcare reaction has been to limit access to clinics and neurology wards to preserve fragile patients with PD and other movement disorders from being infected. In consequence, the use of telemedicine has increased to address the ongoing healthcare needs of patients with chronic illnesses, to reduce in-person clinic visits, and human exposures (among healthcare workers and patients). Many European Union and Asian countries and the United States (US) have expanded laws and regulations to permit greater adoption of telemedicine systems, providing increased guidance on digital health technologies and cybersecurity expectations and expanded reimbursement options [40]. In this regard, many organizations, including the American Academy of Neurology and the MDS, have issued telemedicine guidelines [41, 42].

The recent survey conducted by the MDS Telemedicine Study Group during the pandemic suggested that overall, there was a global increase in all forms of telemedicine for movement disorders, across low-to-high income countries, as an immediate response to the COVID-19 Pandemic. Outpatient visits were converted to phone calls or video visits in many countries. Members from 40 countries reported changes in national policy regarding telemedicine during the pandemic. South Korea legalized phone call visits. Paradoxically, some video visits in Canada had to be converted to phone calls when remote telemedicine clinics were shut down due to the pandemic; on the other hand, reimbursement for telemedicine increased in other regions of Canada [39]. However, questions remain about the longevity of changes in regulations and reimbursement practices as the World moves past the COVID-19 pandemic.

\section{CURRENT BARRIERS AND CHALLENGES}

Despite the growth of telemedicine during the $\mathrm{CO}$ VID-19 pandemic, many challenges to widespread implementation exist (Table 1). Technical challenges, privacy concerns, regulations and reimbursement were still cited as barriers all over the world [39]/Video examinations are often sufficient for stable patients with a known diagnosis, but in complex cases, the examination of eye movements, tone, strength, reflexes, and postural stability are necessary for accurate diagnosis and management. Some patients will have privacy concerns, limited technological savvy, fear of loss of a personal connection, or uneasiness about communicating sensitive information. Patient comfort with these aspects of telemedicine and acceptance of telemedicine will likely vary among different socioeconomic and cultural groups, though there is little data to further guide practitioners in this regard $[5,12]$. For example, patients and doctors resistance and lack of awareness have been described as the main challenges of telemedicine use in Middle Eastern countries [43]. Patients often require technological assistance with the visit, which may not be feasible in many practices. Poor audio or video quality related to unstable internet connections is 
Table 1

Perspectives and barriers of telemedicine for Parkinson's disease

Perspectives of telemedicine for PD
1. Feasibility, the percentage of completed
virtual visits as scheduled.
2. Cost effectiveness; saving time, travel miles \& costs.
3. Global outcome: assessment, management, improving
quality of life, access to health care
4. Patients' perception and satisfaction.
5. Physicians' perception and acceptance
Barriers of telemedicine for PD:
1. Technological limitations, mainly Lack
of high-speed internet
2. Patient need for equipment and training/assistance
3. Patient nonacceptance and unawareness,
cultural barriers
4. Privacy concerns
5. Restrictive regulations
6. Lack of reimbursement
7. Limited examination e.g., rigidity, postural instability.

disruptive to the experience of patients and providers and can happen even where broadband access is widely available.

Despite the high satisfaction rates in the literature, many neurologists are skeptical that the care they can provide is adequate, especially in complex new patients requiring a diagnosis. Furthermore, there is fear that physicians will perceive this time as spent with computers rather than with patients, and that encounters will feel more transactional than personal [44]. There is concern that difficult conversations about prognosis will be made even more difficult by video [44]. Though data suggests the personal connection is not lost $[6,8]$. data to prove or disprove the remaining fears is lacking. Certain patients, such as those with cognitive problems and speech or hearing impairment, may be less likely to have a positive experience with telemedicine. Indeed, not every patient is a good candidate for telemedicine visits, if they are capable of being seen in person.

Both globally and within individual countries, there are large disparities in access to computers, mobile devices, and reliable broadband internet, known as the digital divide. According to a UN-backed report from the Broadband Commission for Sustainable Development, $54.8 \%$ of households worldwide are connected to the internet, some at a speed of only $256 \mathrm{kbps}$; while 3.7 billion people remain unconnected, most of whom reside in developing countries [45]. Determinants of disparities in internet access have been found to include socioeconomic factors and rural versus urban residence, though it should be noted that even within urban areas, there is reduced access among lower income levels [46]. Thus, while telemedicine holds clear promise for bridging solely geographic barriers, reaching the majority of those without access to care will also require bridging this digital divide.

On a regional level, policies governing reimbursement for providers, privacy laws, licensure, and malpractice insurance coverage can pose barriers to telemedicine implementation [39]. In locations or healthcare systems in which reimbursement for telemedicine services equals that of office visits, such as in Canada or the US Veterans Affairs system, telemedicine has thrived; whereas elsewhere in the US, where reimbursement was very restricted prior to the pandemic, telemedicine programs were small and scattered [5]. Restrictive licensure or credentialing requirements can impede the delivery of telemedicine care across state or province lines and into nursing facilities. While there is optimism that policies broadening telemedicine coverage in recent months will endure beyond the pandemic, this is not certain, and more far-reaching policy changes that address licensure, privacy, and the digital divide are needed.

\section{FUTURE PERSPECTIVES}

Despite the considerable challenges, telemedicine presents several opportunities for improving and restructuring the delivery of PD care. To expand specialty care access to those who are geographically isolated or homebound, telemedicine can also bring the focus of care to the patient's home and community, especially when paired with wearable technologies, facilitating a paradigm shift in care described by Bloem et al. [47] Web-based monitoring and adjustment of advanced therapies such as DBS will expand telemedicine to this population. Multidisciplinary clinics, including rehabilitative services and palliative care clinics for homebound patients with advanced disease, can be conducted via telemedicine without requiring multiple specialists and the patient to be in the same location; similarly, family members in other locations can also be present [48]. Observations of patients in their home settings may translate into recommendations more relevant to their daily lives. Clinical trial visits could potentially be done remotely, not only relieving the patient of travel burden, but centralizing data collection and regulatory procedures, thereby reducing inter-center variability and administrative costs [5, 10]. In all of these settings, wearable technologies and mobile applications 
can be used in conjunction with telemedicine to supplement video examinations, enhance disease monitoring, and increase patient engagement. Patient education activities and support groups can be offered not just based on location but based on demographics and disease stage, allowing patients to build a virtual community without geographic constraints.

Much work is needed to overcome barriers and facilitate this expansion of telemedicine. The use of telemedicine beyond the US, Canada, and Europe must be expanded and studied. Policy changes have been spurred forward by the pandemic, but continued local advocacy is needed to ensure reimbursement and lifting of regulatory restrictions going forward. Though the data supports cost savings of telemedicine for patients with PD $[6,8]$, and there is literature supporting the cost-effectiveness of telemedicine in non-Parkinson's patients [49], data regarding costeffectiveness of telemedicine for PD care are lacking, and would facilitate reimbursement from payors. Such changes will increase provider utilization, which will thereby increase patient awareness, acceptance, and demand. Decisions regarding the choice of technology used for telemedicine by providers should take into consideration accessibility to the widest range of socioeconomic and cultural groups. As physicians, we must ensure that as technology advances and more sophisticated tools become available, we do not lose sight of the fundamental goal of improving access to care for those most in need.

\section{CONFLICT OF INTEREST/DISCLOSURE}

Esther Cubo: Spanish government grants (Fondo de Investigación Sanitaria 2020-2023), Travel grants (Allergan, Boston, Abbvie).

Meredith Spindler: Clinical trial funding (Abbvie, US WorldMeds, Sanofi, Abbott, Insightec)

Ali Shalash: no relevant financial disclosures.

\section{REFERENCES}

[1] Collaborators GBDN (2019) Global, regional, and national burden of neurological disorders, 1990-2016: A systematic analysis for the Global Burden of Disease Study 2016. Lancet Neurol 18, 459-480.

[2] Khalid S, Varade P, Bhattacharya P, Madhavan R (2015) International teleneurology. In Teleneurology in Practice, Tsao J, Demaerschalk B, eds. Springer, New York, NY.

[3] https://www.who.int/goe/publications/goe_telemedicine_ 2010.pdf. Accessed on 24 July 2020.

[4] Burke JF, Albin RL (2011) Do neurologists make a difference in Parkinson disease care? Neurology 77, 814-815.
[5] Achey M, Aldred JL, Aljehani N, Bloem BR, Biglan KM, Chan P, Cubo E, Dorsey ER, Goetz CG, Guttman M, Hassan A, Khandhar SM, Mari Z, Spindler M, Tanner CM, van den Haak P, Walker R, Wilkinson JR, International Parkinson and Movement Disorder Society Telemedicine Task Force (2014) The past, present, and future of telemedicine for Parkinson's disease. Mov Disord 29, 871-883.

[6] Beck CA, Beran DB, Biglan KM, Boyd CM, Dorsey ER, Schmidt PN, Simone R, Willis AW, Galifianakis NB, Katz M, Tanner CM, Dodenhoff K, Aldred J, Carter J, Fraser A, Jimenez-Shahed J, Hunter C, Spindler M, Reichwein S, Mari Z, Dunlop B, Morgan JC, McLane D, Hickey P, Gauger L, Richard IH, Mejia NI, Bwala G, Nance M, Shih LC, Singer C, Vargas-Parra S, Zadikoff C, Okon N, Feigin A, Ayan J, Vaughan C, Pahwa R, Dhall R, Hassan A, DeMello S, Riggare SS, Wicks P, Achey MA, Elson MJ, Goldenthal S, Keenan HT, Korn R, Schwarz H, Sharma S, Stevenson EA, Zhu W (2017) National randomized controlled trial of virtual house calls for Parkinson disease. Neurology 89, $1152-1161$

[7] Dorsey ER, Venkataraman V, Grana MJ, Bull MT, George BP, Boyd CM, Beck CA, Rajan B, Seidmann A, Biglan KM (2013) Randomized controlled clinical trial of "virtual house calls" for Parkinson disease. JAMA Neurol 70, 565570.

[8] Korn RE, Wagle Shukla A, Katz M, Keenan HT, Goldenthal S, Auinger P, Zhu W, Dodge M, Rizer K, Achey MA, Byrd E, Barbano R, Richard I, Andrzejewski KL, Schwarz HB, Dorsey ER, Biglan KM, Kang G, Kanchana S, Rodriguez R, Tanner CM, Galifianakis NB (2017) Virtual visits for Parkinson disease: A multicenter noncontrolled cohort. Neurol Clin Pract 7, 283-295.

[9] Hanson RE, Truesdell M, Stebbins GT, Weathers AL, Goetz CG (2019) Telemedicine vs office visits in a movement disorders clinic: Comparative satisfaction of physicians and patients. Mov Disord Clin Pract 6, 65-69.

[10] Dorsey ER, Wagner JD, Bull MT, Rizzieri A, Grischkan J, Achey MA, Sherer T, Chowdhury S, Meunier C, Cappelletti L, Rocker C, Richard IH, Schwarz H, Kang G, Ahmad SH, Biemiller RA, Biglan KM (2015) Feasibility of virtual research visits in Fox Trial Finder. J Parkinsons Dis $\mathbf{5}$, 505-515.

[11] Samii A, Ryan-Dykes P, Tsukuda RA, Zink C, Franks R, Nichol WP (2006) Telemedicine for delivery of health care in Parkinson's disease. J Telemed Telecare 12, 16-18.

[12] Ben-Pazi H, Browne P, Chan P, Cubo E, Guttman M, Hassan A, Hatcher-Martin J, Mari Z, Moukheiber E, Okubadejo NU, Shalash A (2018) The promise of telemedicine for movement disorders: An interdisciplinary approach. Curr Neurol Neurosci Rep 18, 26.

[13] Wilkinson JR, Spindler M, Wood SM, Marcus SC, Weintraub D, Morley JF, Stineman MG, Duda JE (2016) High patient satisfaction with telehealth in Parkinson disease: A randomized controlled study. Neurol Clin Pract 6, 241251.

[14] Spear KL, Auinger P, Simone R, Dorsey ER, Francis J (2019) Patient views on telemedicine for Parkinson disease. J Parkinsons Dis 9, 401-404.

[15] Mammen JR, Elson MJ, Java JJ, Beck CA, Beran DB, Biglan KM, Boyd CM, Schmidt PN, Simone R, Willis AW, Dorsey ER (2018) Patient and physician perceptions of virtual visits for Parkinson's disease: A qualitative study. Telemed $J$ E Health 24, 255-267.

[16] Shalash A, Fathy M, Dawood N, Hamid E (2020) Adopting virtual visits for Parkinson's disease patients during the 
COVID-19 pandemic in a developing country. Front Neurol 11, 582613 .

[17] Dorsey ER, Deuel LM, Voss TS, Finnigan K, George BP, Eason S, Miller D, Reminick JI, Appler A, Polanowicz J, Viti L, Smith S, Joseph A, Biglan KM (2010) Increasing access to specialty care: A pilot, randomized controlled trial of telemedicine for Parkinson's disease. Mov Disord 25, 1652-1659.

[18] Biglan KM, Voss TS, Deuel LM, Miller D, Eason S, Fagnano M, George BP, Appler A, Polanowicz J, Viti L, Smith S, Joseph A, Dorsey ER (2009) Telemedicine for the care of nursing home residents with Parkinson's disease. Mov Disord 24, 1073-1076.

[19] Cubo E, Gabriel-Galan JM, Martinez JS, Alcubilla CR, Yang C, Arconada OF, Perez NM (2012) Comparison of office-based versus home Web-based clinical assessments for Parkinson's disease. Mov Disord 27, 308-311.

[20] Dorsey ER, Darwin KC, Mohammed S, Donohue S, Tethal A, Achey MA, Ward S, Caughey E, Conley ED, Eriksson N, Ravina B (2015) Virtual research visits and directto-consumer genetic testing in Parkinson's disease. Digit Health 1, 2055207615592998.

[21] Stillerova T, Liddle J, Gustafsson L, Lamont R, Silburn P (2016) Remotely assessing symptoms of Parkinson's disease using videoconferencing: A feasibility study. Neurol Res Int 2016, 4802570.

[22] Abdolahi A, Bull MT, Darwin KC, Venkataraman V, Grana MJ, Dorsey ER, Biglan KM (2016) A feasibility study of conducting the Montreal Cognitive Assessment remotely in individuals with movement disorders. Health Informatics $J$ 22, 304-311.

[23] Marzinzik F, Wahl M, Doletschek CM, Jugel C, Rewitzer C, Klostermann F (2012) Evaluation of a telemedical care programme for patients with Parkinson's disease. J Telemed Telecare 18, 322-327.

[24] Espay AJ, Bonato P, Nahab FB, Maetzler W, Dean JM, Klucken J, Eskofier BM, Merola A, Horak F, Lang AE, Reilmann R, Giuffrida J, Nieuwboer A, Horne M, Little MA, Litvan I, Simuni T, Dorsey ER, Burack MA, Kubota K, Kamondi A, Godinho C, Daneault JF, Mitsi G, Krinke L, Hausdorff JM, Bloem BR, Papapetropoulos S (2016) Technology in Parkinson's disease: Challenges and opportunities. Mov Disord 31, 1272-1282.

[25] Siegert C, Hauptmann B, Jochems N, Schrader A, Deck R (2019) ParkProTrain: An individualized, tablet-based physiotherapy training programme aimed at improving quality of life and participation restrictions in PD patients - a study protocol for a quasi-randomized, longitudinal and sequential multi-method study. BMC Neurol 19, 143.

[26] van Nimwegen M, Speelman AD, Overeem S, van de Warrenburg BP, Smulders K, Dontje ML, Borm GF, Backx FJ, Bloem BR, Munneke M (2013) Promotion of physical activity and fitness in sedentary patients with Parkinson's disease: Randomised controlled trial. BMJ 346, f576.

[27] Ellis T, Latham NK, DeAngelis TR, Thomas CA, SaintHilaire M, Bickmore TW (2013) Feasibility of a virtual exercise coach to promote walking in community-dwelling persons with Parkinson disease. Am J Phys Med Rehabil 92, 472-481; quiz 482-475.

[28] Dias AE, Limongi JC, Barbosa ER, Hsing WT (2016) Voice telerehabilitation in Parkinson's disease. Codas 28, 176181.

[29] Quinn R, Park S, Theodoros D, Hill AJ (2019) Delivering group speech maintenance therapy via telerehabilitation to people with Parkinson's disease: A pilot study. Int J Speech Lang Pathol 21, 385-394.

[30] Ward EC, Sharma S, Burns C, Theodoros D, Russell T (2012) Managing patient factors in the assessment of swallowing via telerehabilitation. Int J Telemed Appl 2012, 132719.

[31] Sharma S, Ward EC, Burns C, Theodoros D, Russell T (2013) Assessing dysphagia via telerehabilitation: Patient perceptions and satisfaction. Int J Speech Lang Pathol 15, 176-183.

[32] Dobkin RD, Interian A, Durland JL, Gara MA, Menza MA (2018) Personalized telemedicine for depression in Parkinson's disease: A pilot trial. J Geriatr Psychiatry Neurol 31, 171-176.

[33] Jitkritsadakul O, Rajalingam R, Toenjes C, Munhoz RP, Fasano A (2018) Tele-health for patients with deep brain stimulation: The experience of the Ontario Telemedicine Network. Mov Disord 33, 491-492.

[34] Zhang C, Zhang Y, Zhan S, Li D, Jin H, Denys D, Sun B (2018) Telemedical deep brain stimulation: Merits and limitations. Stereotact Funct Neurosurg 96, 272273.

[35] Willows T, Dizdar N, Nyholm D, Widner H, Grenholm P, Schmiauke U, Urbom A, Groth K, Larsson J, Permert J, Kjellander S (2017) Initiation of levodopa-carbidopa intestinal gel infusion using telemedicine (video communication system) facilitates efficient and well-accepted home titration in patients with advanced Parkinson's disease. J Parkinsons Dis 7, 719-728.

[36] Cubo E, Doumbe J, Lopez E, Lopez GA, Gatto E, Persi G, Guttman M (2017) Telemedicine enables broader access to movement disorders curricula for medical students. Tremor Other Hyperkinet Mov $(N Y) \mathbf{7}, 501$.

[37] Cubo E, Doumbe J, Njiengwe E, Onana P, Garona R, Alcalde J, Seco J, Mariscal N, Epundugu BM, Cubo S, Coma MJ (2015) A Parkinson's disease tele-education program for health care providers in Cameroon. J Neurol Sci 357, 285-287.

[38] Hassan A, Dorsey ER, Goetz CG, Bloem BR, Guttman M, Tanner CM, Mari Z, Pantelyat A, Galifianakis NB, Bajwa JA, Gatto EM, Cubo E (2018) Telemedicine use for movement disorders: A global survey. Telemed $J$ E Health 24, 979-992.

[39] Hassan A, Mari Z, Gatto EM, Cardozo A, Youn J, Okubadejo N, Bajwa JA, Shalash A, Fujioka S, Aldaajani Z, Cubo E, International Telemedicine Study Group (2020) Global survey on telemedicine utilization for movement disorders during the COVID-19 pandemic. Mov Disord 25, 1701-1711.

[40] Rockwell KL, Gilroy AS (2020) Incorporating telemedicine as part of COVID-19 outbreak response systems. Am J Manag Care 26, 147-148.

[41] Telemedicine in Your Movement Disorders Practice. Available online at: https://www.movementdisorders.org/ MDS/About/Committees-Other-Groups/Telemedicinein-Your-Movement-Disorders-Practice-A-Step-by-StepGuide.htm (accessed 22 July 2020).

[42] Telemedicine and COVID-19 Implementation Guide. Available at https://www.aan.com/siteassets/home-page/toolsand-resources/practicing-neurologist-administrators/tele medicine-and-remote-care/20-telemedicine-and-covid19v103.pdf. Accessed on 22 July 2020.

[43] Alajlani M, Clarke M (2013) Effect of culture on acceptance of telemedicine in Middle Eastern countries: Case study of Jordan and Syria. Telemed J E Health 19, 305-311. 
[44] Mulroy E, Menozzi E, Lees AJ, Lynch T, Lang AE, Bhatia KP (2020) Reply to: "A new day: The role of telemedicine in reshaping care for persons with movement disorders". Mov Disord 35, 1903-1904.

[45] State of Broadband Report (2019): Broadband as a Foundation for Sustainable Development. ITU/UNESCO Broadband Commission for Sustainable Development, International Telecommunication Union and United Nations Educational, Scientific and Cultural Organization, Geneva.

[46] Reddick CG, Enriquez R, Harris RJ, Sharma B (2020) Determinants of broadband access and affordability: An analysis of a community survey on the digital divide. Cities 106, 102904.
[47] Bloem BR, Henderson EJ, Dorsey ER, Okun MS, Okubadejo N, Chan P, Andrejack J, Darweesh SKL, Munneke M (2020) Integrated and patient-centred management of Parkinson's disease: A network model for reshaping chronic neurological care. Lancet Neurol 19, 623-634.

[48] Katz M (2020) Telehealth increases access to palliative care for people with Parkinson's disease and related disorders. Ann Palliat Med 9, S75-S79.

[49] Eze ND, Mateus C, Cravo Oliveira Hashiguchi T (2020) Telemedicine in the OECD: An umbrella review of clinical and cost-effectiveness, patient experience and implementation. PLoS One 15, e0237585. 